Bangl. J. Vet. Med. (2006): 47-51

\title{
EFFECTS OF VARIOUS ANAESTHETIC COMBINATIONS ON PAIN MANAGEMENT AFTER OVARIOHYSTERECTOMY IN BITCHES
}

\author{
M. S. Islam ${ }^{1}$ M. A. Hashim and M. S. Alam² \\ Department of Surgery and Obstetrics, Faculty of Veterinary Science, Bangladesh Agricultural University, \\ Mymensingh-2202, Bangladesh
}

\begin{abstract}
This study was carried out for the assessment of various anaesthetic combinations on pain management after ovariohysterectomy and to find out the best combination of premedication and anaesthetic drugs for prevention of pain in dogs during the period from May to October 2005 in the Department of Surgery and Obstetrics, Faculty of Veterinary Science, Bangladesh Agricultural University, Mymensingh-2202, Bangladesh. Twenty seven bitches were allocated into three equal groups. The treatment groups were the Atropine-Ketamine-Xylazine (AKX), Atropine-DiazepamThiopentone (ADT), and Atropine-Thiopentone-Xylazine (ATX). As local analgesic, 2\% lignocaine hydrochloride was administered before closing the external skin wound during experiment in all groups. The levels of analgesia and wound tenderness were assessed by dynamic interactive visual analogue scale (DIVAS). Parametric variables were analyzed using Student's t-test, paired sample t-test and one-way ANOVA in the appropriate cases. Overall, postoperative pain and wound tenderness score increased significantly $(\mathrm{p}<0.01)$ irrespective of groups. Pain decreased significantly $(\mathrm{p}<$ $0.01)$ in ADT group compared to other two groups. Similarly, wound tenderness decreased significantly $(\mathrm{p}<0.01)$ in ADT group at each observation compared to other two groups (ATX and AKX). No adverse event or reaction was observed through the courses of the study. It was demonstrated that Atropine-Diazepam-Thiopentone group provided an excellent analgesia compared to AKX and ATX. A multimodal approach of anaesthesia during ovariohysterectomy in bitches is suggested for prevention of pain.
\end{abstract}

Key words: Anaesthetic, pain, ovariohysterectomy, bitch

\section{INTRODUCTION}

Ovariohysterectomy (OHE) is a common procedure in veterinary practice (Fox et al., 2000). It is generally accepted that some degrees of postoperative pain will be present (Lascelles et al., 1998). The degree of pain may vary with the amount of trauma to tissue and with the pain threshold of the individual animal (Mathews et al., 2001). The analgesia and anaesthesia need to be complimentary.

Current attitude about animal welfare has increased the importance of pain management in livestock. Even minor surgical procedures in livestock are now performed using a combination of regional, local or general anaesthesia together with interrupted post- surgical analgesia. Attitudinal changes toward animal suffering have necessitated an understanding of pain modulation by the veterinarian and willingness of the owners to incur extra cost in order to comfort animals (George, 2003). Therefore, the present study was designed to evaluate various anaesthetic combinations on pain management after ovariohysterectomy and to find out the best combination of premedication and anaesthetic drugs for control of pain in bitches.

\section{MATERIALS AND METHODS}

During the period May to October 2005, twenty-seven bitches were caught from the local area of Bangladesh Agricultural University, Mymensingh-2202 and the experiment was done in the Department of Surgery and Obstetrics, Faculty of Veterinary Science, Bangladesh Agricultural University, Mymensingh-2202. Ages of the bitches ranged from 1.5 to 2 years (determination of age on the basis of dental formula). Body weight ranged from 12 to $16 \mathrm{~kg}$ with a median of $14 \mathrm{~kg}$.

Present address: ${ }^{1}$ Department of Physiology, Biochemistry and Pharmacology, Dinajpur Government Veterinary College, Basherhat, Dinajpur-5200, and ${ }^{2}$ Holy Family Red Crescent Hospital, Dhaka 
The animals were divided equally into three groups as AKX (Atropine Ketamine Xylazine), ADT (Atropine Diazepam Thiopentone), and ATX (Atropine Thiopentone Xylazine). Every bitch received $0.05 \mathrm{mg} / \mathrm{kg}$ atropine intramuscularly. In AKX group five minutes later ketamine was given at $5.5 \mathrm{mg} / \mathrm{kg}$ body weight together with 1 $\mathrm{mg} / \mathrm{kg}$ xylazine intravenously. In the ADT group diazepam was given intramuscularly at $1 \mathrm{mg} / \mathrm{kg}$ and ten minutes after thiopentone was given intravenously at $20 \mathrm{mg} / \mathrm{kg}$. In the ATX group at $1 \mathrm{mg} / \mathrm{kg}$ xylazine was given intravenously and seven minutes after thiopentone was given intravenously at $20 \mathrm{mg} / \mathrm{kg}$. The above anaesthetic combinations were used for general anaesthesia and as local analgesic lignocaine hydrochloride was used in all groups. During anaesthesia, all the bitches were monitored for the depth of anaesthesia, pulse and respiratory rate. Physical examination was performed in all groups prior to anaesthesia and only the apparently healthy bitches were selected. Baseline values were recorded for heart rate, respiratory rate, and rectal temperature. Pricking with needle, pressing with palm respectively made the assessment of pre-operative pain and wound tenderness for baseline value just before pre-medication. All these scores were recorded on the dynamic interactive visual analogue scale (DIVAS). All the bitches were scored for signs of pain; wound tenderness at $0.5 \mathrm{hr}$ after pre-medication and at $0.5 \mathrm{hr}, 1.0 \mathrm{hr}$ and $1.5 \mathrm{hr}$ after surgery. Parametric variables were analyzed statistically as Student's t-test was used to analyze the effect of different treatment at different interval, Student's paired t-test was performed to compare the effect of different treatments at each of the assessment time and analysis of variance (ANOVA) was carried out to find the significant variation between effects in different assessment time.

\section{RESULTS AND DISCUSSION}

The mean value of heart rate (HR), respiration rate (RR), rectal temperature (RT) was 80/min, 22/ min, and $101^{\circ} \mathrm{F}$ respectively. There were no significant differences between groups regarding the total amount of lignocaine given. No adverse effect or reaction to the treatment was observed throughout the study. No dogs were given any supplemental analgesics.

\section{Dynamic interactive visual analogue scale (DIVAS)-pain scores}

There were significant differences of DIVAS pain scores (Fig. 1) at each assessment time with low values for pain occurring at 0.5 hour and gradually increasing through other observation periods and reached the peak at 1.5 hour post-operatively in all the groups (Table 1 ).

Table 1. Pre- and post-operative DIVAS- pain scores in different groups

\begin{tabular}{|c|c|c|c|c|c|}
\hline \multirow{3}{*}{$\begin{array}{l}\text { Groups } \\
(n=9)\end{array}$} & \multicolumn{5}{|c|}{ Pain scores (millimeters) (Mean \pm SD) } \\
\hline & \multicolumn{2}{|c|}{ Pre-medication } & \multicolumn{3}{|l|}{ Post-operation } \\
\hline & Before & After $0.5 \mathrm{hr}$ & $0.5 \mathrm{hr}$ & $1.0 \mathrm{hr}$ & $1.5 \mathrm{hr}$ \\
\hline $\mathrm{AKX}$ & $00 \pm 00$ & $00 \pm 00$ & $28.9 \pm 1.56^{* *}$ & $37.0 \pm 1.54 * *$ & $43.4 \pm 1.33^{* *}$ \\
\hline ADT & $00 \pm 00$ & $00 \pm 00$ & $18.9 \pm 0.39 * *$ & $24.0 \pm 1.41^{* *}$ & $30.7 \pm 1.00 * *$ \\
\hline ATX & $00 \pm 00$ & $00 \pm 00$ & $23.0 \pm 2.12^{* *}$ & $30.2 \pm 1.39 * *$ & $37.9 \pm 1.39 * *$ \\
\hline
\end{tabular}

$\mathrm{n}=$ Number of bitches in each group, ${ }^{* *}$ Significant at $\mathrm{p}<0.01$, AKX $=$ Atropine Ketamine Xylazine, ADT $=$ Atropine Diazepam Thiopentone, and ATX =Atropine Thiopentone Xylazine.

The pre-operative pain scores were 0 in all groups. In ADT group, DIVAS-pain scores were (in millimeter) $18.9 \pm 0.39,24.0 \pm 1.41$ and $30.7 \pm 1.00$ at 0.5 hour, 1.0 hour, and 1.5 hour after operation, respectively (Table 1 ). Comparatively, ADT treated dogs had significantly $(\mathrm{p}<0.01)$ lower pain score at $0.5 \mathrm{hr}$ after surgery than AKX and ATX treated dogs. Regarding ATX treated dogs, DIVAS-pain scores were 23.0 $\pm 2.12,30.2 \pm 1.39$ and $37.9 \pm 1.39$ at 0.5 hour, 1.0 hour, and 1.5 hour post-operatively, respectively (Table 1$)$. The ATX group had significantly $(\mathrm{p}<0.01)$ higher pain score than ADT but significantly $(\mathrm{p}<0.01)$ lower pain score than AKX group. 
In AKX group, DIVAS-pain scores were 28.9 $\pm 1.56,37.0 \pm 1.54$ and $43.4 \pm 1.33$ at 0.5 hour, 1.0 hour, and 1.5 hour after operation respectively (Table 1$)$ and were significantly higher $(\mathrm{p}<0.01)$ than the rest of the treatment groups. This may reflect the idea that pain started after the animal become conscious from the general anaesthesia and the local analgesic used was short acting. The result of this study demonstrated that AtropineDiazepam-Thiopentone (ADT) group had significant lower scores compared to Atropine-Ketamine-Xylazine (AKX) and Atropine-Thiopentone-Xylazine (ATX) groups at each postoperative assessment time. Pain response in ADT group was significantly lower may be due to synergistic effect of the drugs used. The present study is in agreement with the study of Dahl and Kelhet (1993) and Slingsby and Waterman-Pearson (2001) who suggested a multimodal or balanced analgesic agent for the best pain control. Local analgesic used as lignocaine hydrochloride seemed to prevent postoperative pain until two hours so this way followed an additional analgesia with any suitable analgesics.

Overall, the pain scored in the study was not particularly high. The Atropine-Ketamine-Xylazine group (AKX) scored an average of 43.4 out of 100 on the DIVAS. The DIVAS pain score was subjective, but would fall about half way between 'no pain' and 'worst imaginable pain' so it might be considered as moderate pain. This moderate level of pain corresponds with the expected findings of Zimmerman (1986) who reported that there was mild to moderate level of pain after abdominal surgery in farm animals.

The responsive and interactive behaviors after surgical wound palpation were recently considered a vital determinant for assessing degree of postoperative pain. Here the DIVAS was used which differ visual analogue scale (VAS) only due to incorporated behaviours (Hashim, 2004). The other scale is thought to be parallel with DIVAS previously used in cats in IVAS (Interactive Visual Analogue Scale) (Cambridge et al., 2000). The responsive of interactive behavioral manipulation of surgical wound in the present study varied according to the severity of pain and the most dominant are hereby include biting of the wound, painful crying, falling on the ground on the opposite side of the wound, regaining of the standing position and posture. These findings were consistence with the result of Wright and Woodson (1990).

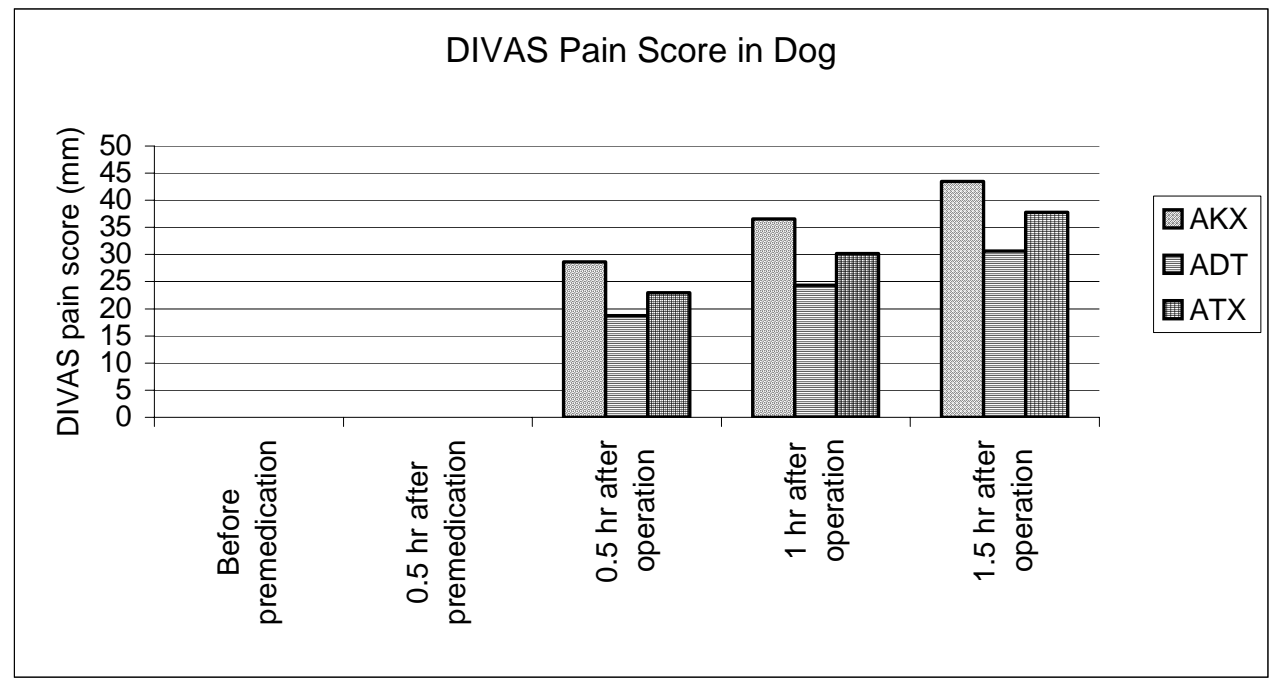

Fig. 1. Pre- and post-operative DIVAS-pain scores in different treatment groups.

$(\mathrm{AKX}=$ Atropine-Ketamine-Xylazine, $\mathrm{ADT}=$ Atropine-Diazepam-Thiopentone, and ATX = Atropine-Thiopentone -Xylazine)

\section{Dynamic Interactive Visual Analogue Scale (DIVAS)-wound tenderness score}

There was significant $(\mathrm{p}<0.01)$ increase in wound tenderness scores across each time among AKX, ADT and ATX groups with a low value occurring at 0.5 hour and gradually increasing through other assessment time and reached the peak at 1.5 hour postoperatively (Table 2). 
Table 2. Pre- and post-operative DIVAS- wound tenderness in different groups

\begin{tabular}{|c|c|c|c|c|c|}
\hline \multirow{3}{*}{$\begin{array}{l}\text { Groups } \\
(\mathrm{n}=9)\end{array}$} & \multicolumn{5}{|c|}{ Wound tenderness (millimeters) (Mean \pm SD) } \\
\hline & \multicolumn{2}{|c|}{ Pre-medication } & \multicolumn{3}{|l|}{ Post-operation } \\
\hline & Before & After $0.5 \mathrm{hr}$ & $0.5 \mathrm{hr}$ & $1.0 \mathrm{hr}$ & $1.5 \mathrm{hr}$ \\
\hline $\mathrm{AKX}$ & $00 \pm 00$ & $00 \pm 00$ & $15.3 \pm 1.58 * *$ & $26.0 \pm 1.50 * *$ & $42.9 \pm 3.63 * *$ \\
\hline ADT & $00 \pm 00$ & $00 \pm 00$ & $08.4 \pm 1.33 * *$ & $18.4 \pm 1.51^{* *}$ & $23.0 \pm 2.69 * *$ \\
\hline ATX & $00 \pm 00$ & $00 \pm 00$ & $12.3 \pm 1.87^{* * *}$ & $21.4 \pm 1.51^{* *}$ & $25.3 \pm 1.41^{* *}$ \\
\hline
\end{tabular}

$\mathrm{n}=$ Number of bitches in each group, ${ }^{*}$ Significant at $\mathrm{p}<0.01$, AKX $=$ Atropine Ketamine Xylazine, ADT $=$ Atropine Diazepam Thiopentone, and ATX =Atropine Thiopentone Xylazine.

Table 2 shows the wound tenderness scores of Atropine-Ketamine-Xylazine (AKX), Atropine-DiazepamThiopentone (ADT), and Atropine-Thiopentone-Xylazine (ATX) at individual assessment time. DIVAS wound tenderness at preoperative period were 0 in all the treatment groups comparatively, at 0.5 hour after operation ADT group had significantly $(\mathrm{p}<0.01)$ lower wound tenderness scores than each of ATX and AKX groups (Fig. 2). Wound tenderness was found concurrently lower along generalised pain score corresponding compared to each other group. Also wound tenderness was increased in response to time. However, this did not always correspond to the DIVAS pain score. Some bitches were found higher wound tenderness not exactly correlated that of pain score.

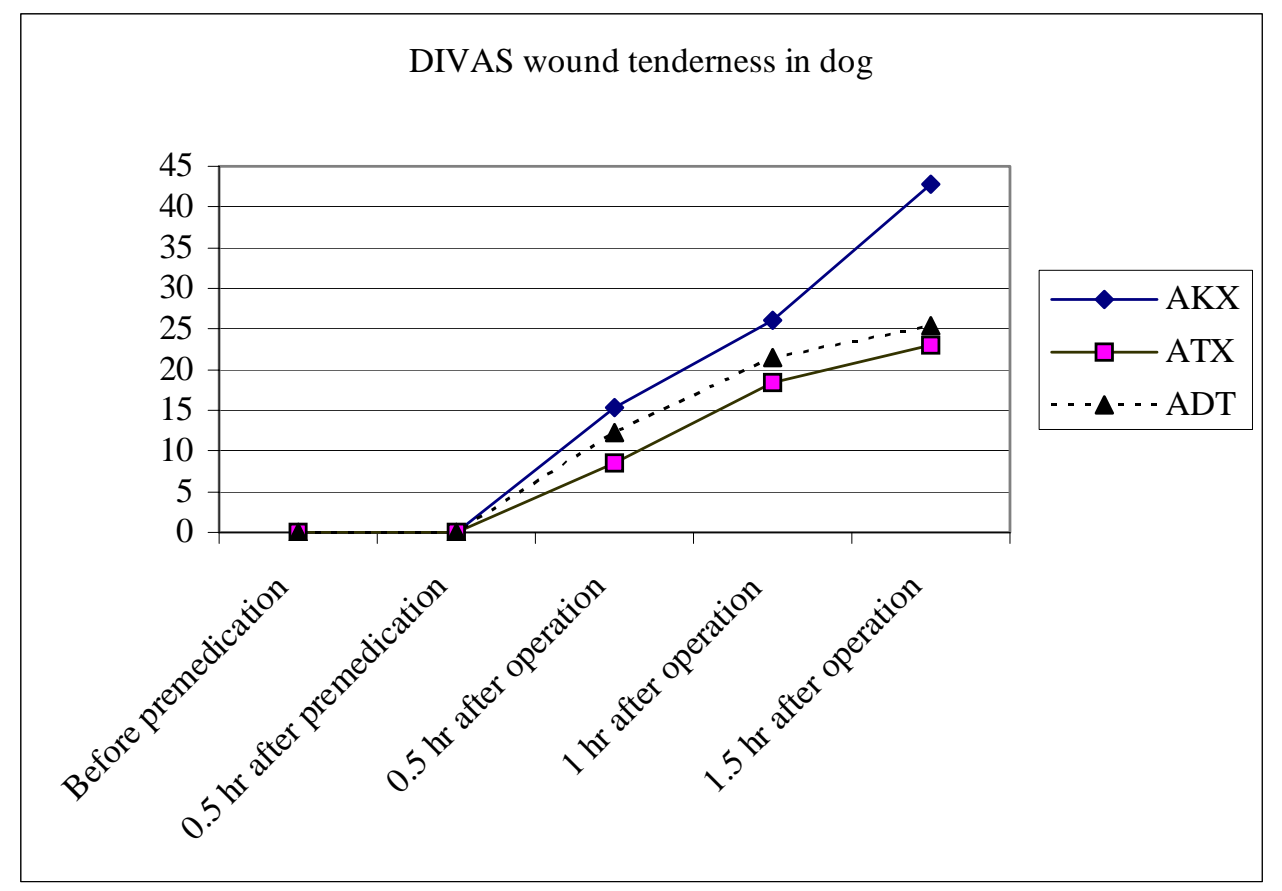

Fig. 2. Pre- and post-operative DIVAS-wound tenderness in different treatment groups. $($ AKX $=$ Atropine-Ketamine-Xylazine, ADT = Atropine-Diazepam-Thiopentone, and ATX = Atropine-Thiopentone -Xylazine). 
From the result it was found that wound tenderness was sufficiently lower $(\mathrm{p}<0.01)$ in Atropine- DiazepamThiopentone (ADT) group compared to AKX and ATX group. It is probably due to relaxation of smooth muscle properties of diazepam. Broadly speaking, there is no rigid explanation of this disparity; the reason may be the onset and duration of action of different types local analgesic used. The Student's ' $t$ '-test for one sample statistics revealed that the DIVAS wound tenderness within each treatment group were increased at each assessment time at 0.5 hour, 1.0 hour and 1.5 hour (Table 2).

Clinically, whether or not the sedation is employed, as an adjunct with general anaesthesia will depend on the species, treatment and health status of animal and magnitude of the procedure. The involvements of diazepam in the modulation of pain mechanism still remain controversial. In present study, it was found that the sedative effect of the Atropine- Diazepam-Thiopentone (ADT) group was better compared with ATX and AKX. Diazepam at a dose of $1 \mathrm{mg} / \mathrm{kg}$ body weight intramuscularly was used in bitches, which greatly facilitated by the reduction of fear and limiting of sudden movement. The sedation observed in this study include irritative crying, decrease response to noise, mild relaxation of jaw, drowsiness, reduce response to pin pricks, slight incoordination and muscle relaxation, dropping of the upper eyelids and sluggish pedal reflexes which corresponds the study reported by Pratap et al. (1997) in goats and Kumar et al. (1999) in yaks.

Pain management after surgery is more likely to be achieved from multimodal approach by using AtropineDiazepam-Thiopentone along with incisional lignocaine hydrochloride as local analgesic.

\section{REFERENCES}

1. Cambridge AJ, Tobias KM, Newberry RC and Darkar AK (2000). Subjective and objective measurements of postoperative pain in cats. Journal of American Veterinary Medical Association 217: 685-690.

2. Dahl JB and Kelhet H (1993). The value of preemptive analgesia in the treatment of postoperative pain. British Journal of Anaesthesia 70: 434-439.

3. Fox SM, Mellor DJ, Stafford KJ and Lowoko CRO (2000). The effects of ovariohysterectomy plus different combinations of halothane anaesthesia and butorphanol analgesia on behavior in the bitch. Research in Veterinary Science 68: 265-274.

4. George LW (2003). Pain control in food animals. In: Recent Advance in Anaesthetic Management of Large Domestic Animals. Edited by E.P. Steffey. International Veterinary Information Service, Ithaca, NY.

5. Hashim MA (2004). The effect of local analgesics for postoperative pain control after ovariohysterectomy in the dog and cat. A project report, Department of Clinical Veterinary Science, University of Bristol, Langford House, Langford, Bristol BS 405 DU, UK. pp 1-8.

6. Kumar A, Nigma JM and Sharma SK (1999). Diazepam sedation in yaks. Indian Veterinary Journal 76: $211-213$.

7. Lascelles BDX, Cripps PJ, Jones A and Waterman-Pearson AE (1998). Efficacy and kinetics of carprofen, given pre- or postoperatively, for the prevention of pain in dogs undergoing ovariohysterectomy. Veterinary Surgery 27: 568-582.

8. Mathews KA, Pettifer G, Foster R and McDonell W (2001). Safety and efficacy of preoperative administration of meloxicam, compared with that of ketoprofen and butorphanol in dogs undergoing abdominal surgery. American Journal of Veterinary Research 62: 882-888.

9. Pratap K, Amarpal, Atithal HP and Singh GR (1997). Clinical evaluation of different preanaesthetics in goats: an experimental study. Indian Veterinary Journal 74: 894-898.

10. Slingsby LS and Waterman-Pearson AE (2001). Analgesic effects in dogs of caprofen and pethidine together compared with the effects of either drug alone. Veterinary Record 148: 441-444.

11. Wright EMJr and Woodson JF (1990). Clinical Assessment of Pain in Laboratory Animals. In: The Experimental Animal in Biomedical Research. $2^{\text {nd }}$ edn., B. E. Rollin and M. L. Essel (Eds.), Vol. I. CRC Press, Boca, Raton. pp 205215.

12. Zimmerman M (1986). Behavioral investigation of pain in animals. In: Assessing pain in farm animals (Proceeding of 1984 Workshop). Edited by IJH Duncan and V Molloy, Commission of European Communities, Luxemburg. pp 16-27. 